\title{
The pharmacokinetics of vancomycin during the initial loading dose in patients with septic shock
}

This article was published in the following Dove Press journal:

Infection and Drug Resistance

22 November 2016

Number of times this article has been viewed

\section{Wasan Katip'}

Sutep Jaruratanasirikul ${ }^{2}$

Sutthiporn

Pattharachayakul ${ }^{3}$

Wibul Wongpoowarak ${ }^{4}$

Arnurai Jitsurong ${ }^{5}$

Aroonrut Lucksiri'

'Department of Pharmaceutical Care, Faculty of Pharmacy, Chiang Mai University, Chiang Mai, ${ }^{2}$ Department of Medicine, Faculty of Medicine,

${ }^{3}$ Department of Clinical Pharmacy,

${ }^{4}$ Department of Pharmaceutical

Technology, Faculty of Pharmaceutical Sciences, ${ }^{5}$ Department of Toxicology, Faculty of Medicine, Prince of Songkla University, Songkla, Thailand

Correspondence: Wasan Katip Department of Pharmaceutical Care, Faculty of Pharmacy, Suthep Road, Chiang Mai University, Chiang Mai 50200, Thailand

Email wasankatip@gmail.com
Objective: To characterize the pharmacokinetics (PK) of vancomycin in patients in the initial phase of septic shock.

Methods: Twelve patients with septic shock received an intravenous infusion of vancomycin 30 $\mathrm{mg} / \mathrm{kg}$ over $2 \mathrm{~h}$. The vancomycin PK study was conducted during the first $12 \mathrm{~h}$ of the regimen. Serum vancomycin concentration-time data were analyzed using the standard model-independent analysis and the compartment model.

Results: For the noncompartment analysis the mean values \pm standard deviation (SD) of the estimated clearance and volume of distribution of vancomycin at steady state were $6.05 \pm 1.06$ $\mathrm{L} / \mathrm{h}$ and $78.73 \pm 21.78 \mathrm{~L}$, respectively. For the compartmental analysis, the majority of vancomycin concentration-time profiles were best described by a two-compartment PK model. Thus, the two-compartmental first-order elimination model was used for the analysis. The mean \pm $\mathrm{SD}$ of the total clearance $(3.70 \pm 1.25 \mathrm{~L} / \mathrm{h})$ of vancomycin was higher than that obtained from patients without septic shock. In contrast, the volume of the central compartment $(8.34 \pm 4.36 \mathrm{~L})$ and volume of peripheral compartment $(30.99 \pm 7.84 \mathrm{~L})$ did not increase when compared with patients without septic shock.

Conclusion: The total clearance of vancomycin was increased in septic shock patients. However, the volume of the central compartment and peripheral compartment did not increase. Consequently, a loading dose of vancomycin should be considered in all patients with septic shock.

Keywords: pharmacokinetics, vancomycin, MRSA, septic shock patients

\section{Introduction}

Septic shock is one of the most lethal illnesses encountered in an intensive care unit (ICU). Especially, in the case of the Sequential (Sepsis-related) Organ Failure Assessment (SOFA) score of $\geq 2$ points, which is associated with an increase in the mortality risk in septic patients in an ICU. Moreover, the primary response in critically ill patients caused by the release of intrinsic mediators by the host as a reaction to bacterial toxins leads to the increase in capillary permeability, edema formation, vasodilatation, and hypotension. These alterations in pathophysiological conditions may result in pharmacokinetic (PK) changes in several antibiotics. ${ }^{1}$

Vancomycin is a relatively hydrophilic antibiotic. In critically ill patients, the leakage of the fluid from the vessels may result in the larger volume of vancomycin distribution, as well as decrease its plasma drug concentration. However, in general, patients with septic shock would aggressively receive fluid resuscitation during the initial phase of septic shock. The overall impacts of these changes were still unknown. Furthermore, in the absence of significant organ dysfunction, renal perfusion of septic shock patients is 
often increased and, consequently, may result in the increased creatinine clearance and elimination of hydrophilic antibiotics. Theoretically, because optimal trough concentration for vancomycin is $15-20 \mathrm{mg} / \mathrm{L}$ and $24-\mathrm{h}$ area under the vancomycin concentration-time curve/minimum inhibitory concentration $\left(\mathrm{AUC}_{24} / \mathrm{MIC}\right) \geq 400 \mu \mathrm{g} \cdot \mathrm{h} / \mathrm{mL}$, these may result in subtherapeutic vancomycin serum concentrations and a corresponding potential for developing antibiotic resistance and/or therapeutic failure. ${ }^{2}$ Currently, despite various vancomycin PK studies in critically ill patients, the data on the PK profiles and dosage requirements of vancomycin in patients with initial phase of septic shock are however limited. ${ }^{3}$ The objective of this study was to evaluate the PK data of vancomycin in patients with an initial phase of septic shock.

\section{Materials and methods Subjects}

This study was conducted at a university-affiliated hospital located in Southern Thailand between January and December 2012 .

The patients were eligible for the study if they:

1) were older than 18 years;

2) developed septic shock:

a) persistent hypotension (systolic blood pressure [SBP] $<90 \mathrm{mmHg}$, mean arterial pressure $<60 \mathrm{mmHg}$ or decreased SBP $40 \mathrm{mmHg}$ from baseline) despite adequate volume resuscitation, in the absence of other causes for hypotension, and

b) presented with more than two of the following clinical findings:

i) heart rate of $>90$ beats $/ \mathrm{min}$;

ii) respiratory rate of $>20$ breaths $/ \mathrm{min}$ or arterial partial pressure of carbon dioxide $\left(\mathrm{PCO}_{2}\right)$ of $<32 \mathrm{mmHg}$;

iii) core temperature of $<36^{\circ} \mathrm{C}$ or $>38^{\circ} \mathrm{C}$; and

iv) white blood cell count of $<4 \times 10^{9}$ or $>12 \times 10^{9}$ cells $/ \mathrm{L}$ or $>10 \%$ immature (band) forms; and

3) received vancomycin in the setting of suspected methicillin-resistant staphylococcus aureus (MRSA) infection.

Patients were excluded from the study if they were: 1) exposed to intravenous (IV) vancomycin within the last 7 days; 2) on hemodialysis; 3 ) on renal replacement therapy (continuous venovenous hemofiltration, continuous venovenous hemodialysis, continuous venovenous hemodiafiltration, slow continuous ultrafiltration, continuous arteriovenous hemodialysis); 4) pregnant; 5) treated for burns; 6) diagnosed with a hematologic malignancy; or 7) allergic to vancomycin. The study protocol was approved by the Ethics Committee of Songklanagarind Hospital, and written informed consent was obtained from each patient. The data recorded on the day when the patients developed septic shock were age, gender, main diagnosis, and SOFA scores. Body weight, mechanical ventilation status, nutritional support, fluid balance, serum albumin, and estimated creatinine clearance (CLCr), according to the Cockroft-Gault method, ${ }^{4}$ as well as concurrent administration of vasoactive drugs were also recorded during the time of septic shock.

\section{Study design}

This is a prospective, non-comparative PK study.

\section{Drug administration}

Vancomycin was reconstituted according to the manufacturer's guidelines. It was diluted into preparations: $1 \mathrm{~g}$ in $100 \mathrm{~mL}$ of normal saline solution. Each subject received a vancomycin loading dose of $30 \mathrm{mg} / \mathrm{kg}$ (based on actual body weight) $2 \mathrm{~h}$ infusion via central line.

\section{Blood sampling}

Blood samples of $\sim 2.5 \mathrm{~mL}$ were obtained each time by direct venipuncture before and at 30,60,120, 130, 140, 160, 180, $210,240,360,540$, and $720 \mathrm{~min}$ after the initiation of vancomycin infusion. All blood samples were allowed to clot and then centrifuged at 2,000 rpm. The serum obtained was stored at $-80^{\circ} \mathrm{C}$ until analyzed.

\section{Vancomycin assays}

Concentrations of vancomycin in serum were determined by fluorescence polarization immunoassay (AxSYM; Abbott Laboratories, Abbott Park, IL, USA). The assay limit of detection of vancomycin was $2 \mu \mathrm{g} / \mathrm{mL}$, and the intraday and interday assay coefficients of variation were $<7 \%$ over the entire calibration range $(7-75 \mu \mathrm{g} / \mathrm{mL})$.

\section{PK analyses}

Vancomycin PK analyses were conducted using two approaches: the noncompartmental modeling (model-independent methods) and the compartmental modeling using Phoenix $^{\circledR}$ WinNonlin $^{\circledR}$ Version 6.3 (Certara $^{\mathrm{TM}}$, St. Louis, MO, USA) to determine the PK parameters of interest in each individual patient.

The elimination rate constant $(\mathrm{Ke})$ of each patient was estimated with linear regression of the last three points which is at least $4 \mathrm{~h}$ after the completion of infusion on the semilogarithmic vancomycin concentration-time plots. The area under the serum concentration-time curve from time zero to $12 \mathrm{~h}\left(\mathrm{AUC}_{0 \rightarrow 12}\right)$ was calculated for each subject by the linear$\log$ trapezoidal rule. The $\mathrm{AUC}_{0 \rightarrow 24}$ at steady state $\left(\mathrm{AUC}_{0 \rightarrow 24, \mathrm{ss}}\right)$ was estimated assuming the patients received the same dose of vancomycin every $24 \mathrm{~h}$ and vancomycin PK remained the 
same. Then, the effects of patients' demographic and clinical data on the PK of vancomycin were explored.

For the model dependent analysis, serum vancomycin concentration-time curves were fit to one, two, and three compartmental first-order elimination models. The Akaiki information criterion (AKI) and the Schwarz Bayesian criterion were used to select the best fit model.

\section{Pharmacodynamics analyses}

The probability of achieving the PD target of $\mathrm{AUC}_{24} / \mathrm{MIC}$ $\geq 400$ in patients with septic shock treated with vancomycin was assessed using $\mathrm{AUC}_{24} / \mathrm{MIC}$ model and parameters estimated from the PK analysis. Simulations of 10,000 patients were conducted with different vancomycin dosages (30 mg/kg loading and $20 \mathrm{mg} / \mathrm{kg}$ subsequent dose every 8 , 12 , and $24 \mathrm{~h}$ ) and MICs different for MRSA to vancomycin.

\section{Statistical analysis}

The correlations between patients' demographic data, clinical data, and PK parameters were assessed via simple linear regression analysis.

\section{Results}

Twelve patients (nine males and three females) were enrolled in the study with a mean age of $57 \pm 19$ years (range $26-86$ years) and mean actual body weight of $62 \pm 9 \mathrm{~kg}$ (range $50-80 \mathrm{~kg}$ ). The characteristics of all patients and the regimens of vancomycin are shown in Table 1.

The semilogarithmic plots of the observed serum vancomycin concentration-time curve are shown in Figure 1. Each line refers to a serum vancomycin concentration-time profile of an individual patient. Ten out of the twelve patients had serum vancomycin concentration monitored for $12 \mathrm{~h}$ after vancomycin administration. Two patients (subject numbers 6 and 10) died before the study completed, and the last vancomycin serum concentrations of them were collected at 4 and $9 \mathrm{~h}$ after infusion was completed. Two out of the ten patients had the observed vancomycin serum concentration at $12 \mathrm{~h}$ after the dose (minimum concentration, $\mathrm{C}_{\text {min }}$ ) within the therapeutic range $(15-20 \mathrm{mg} / \mathrm{L})$, while six patients had the lower $\mathrm{C}_{\text {min }}$ than the therapeutic range $(<15 \mathrm{mg} / \mathrm{L})$. Two patients had the higher observed $\mathrm{C}_{\text {min }}$ than the therapeutic range $(>20 \mathrm{mg} / \mathrm{L})$. Observed and predicted vancomycin concentration versus time plots using two-compartmental model analysis for individual subjects receiving vancomycin $30 \mathrm{mg} / \mathrm{kg}$ infused over $2 \mathrm{~h}$ are shown in Figure 2.

The Ke of each patient was estimated with linear regression of the last three points (at least $4 \mathrm{~h}$ after the completion of infusion) on the semilogarithmic vancomycin concentration-time plots. The noncompartmental analysis was performed in ten patients. The elimination phase cannot be predicted in the other two patients due to insufficient concentration observed during their elimination phases. The area under the serum concentration-time curve (AUC) was calculated by the linear-log trapezoidal rule. The AUCs of non- and two-compartmental model analyses were presented in Tables 2 and 3, respectively. The median terminal half-life was $8.93 \mathrm{~h}$ (range $6.85-15.68 \mathrm{~h}$ ). The median estimate of vancomycin total body clearance at steady state $\left(\mathrm{CLss}=\right.$ dose $\left./ \mathrm{AUC}_{0 \rightarrow \infty}\right)$ was $5.87 \mathrm{~L} / \mathrm{h}$ (range 4.78-8.05), and the median estimate of volume of distribution at steady state (Vss = mean residence time extrapolated to infinity [MRTINF]*total clearance [CL]) was $78.90 \mathrm{~L}$ (range 48.27-111.51 L). Table 2 presents the patients' PK parameter obtained from the noncompartmental analysis.

The relationship of patients' demographic and their clinical outcomes and the values of $\mathrm{PK}$ parameters were explored. Only

Table I Patient characteristics in twelve septic shock patients

\begin{tabular}{|c|c|c|c|c|c|c|c|c|c|}
\hline Patient & Gender & $\begin{array}{l}\text { Age } \\
\text { (years) }\end{array}$ & $\begin{array}{l}\text { Weight } \\
\text { (kg) }\end{array}$ & $\begin{array}{l}\text { Serum } \\
\text { creatinine }(\mathrm{mg} / \mathrm{dL})\end{array}$ & $\begin{array}{l}\text { Fluid } \\
\text { balance }\end{array}$ & $\begin{array}{l}\text { Vasoactive } \\
\text { agent }\end{array}$ & $\begin{array}{l}\text { CLCr } \\
(\mathrm{mL} / \mathrm{min})^{a}\end{array}$ & $\begin{array}{l}\text { SOFA } \\
\text { score }\end{array}$ & $\begin{array}{l}\text { Loading } \\
\text { dose }(\mathbf{m g})\end{array}$ \\
\hline Subject I & $M$ & 79 & 50 & 1.28 & -1015 & NE & 33 & 9 & 1500 \\
\hline Subject 2 & $M$ & 86 & 50 & 1.26 & +457 & DA & 30 & 15 & 1500 \\
\hline Subject 3 & $M$ & 41 & 80 & 4.01 & +1450 & NE & 27 & 19 & 2400 \\
\hline Subject 4 & $M$ & 57 & 67 & 0.99 & +400 & NE & 78 & 13 & 2000 \\
\hline Subject 5 & $\mathrm{~F}$ & 66 & 65 & 1.52 & -740 & NE & 34 & 10 & 2000 \\
\hline Subject 6 & $\mathrm{~F}$ & 55 & 60 & 0.62 & +804 & NE & 96 & 13 & 1800 \\
\hline Subject 7 & $M$ & 50 & 68 & 1.61 & -565 & DA & 53 & 9 & 2000 \\
\hline Subject 8 & $M$ & 26 & 57 & 0.83 & +950 & DA & 109 & 10 & 1700 \\
\hline Subject 9 & $\mathrm{~F}$ & 81 & 57 & 1.59 & +109 & NE & 25 & 18 & 1700 \\
\hline Subject 10 & $M$ & 61 & 60 & 3.01 & +1000 & DA & 22 & 18 & 1800 \\
\hline Subject II & $M$ & 52 & 62 & 0.71 & -980 & NE & 100 & 13 & 1800 \\
\hline Subject 12 & $M$ & 33 & 73 & 1.19 & -1079 & NE & 90 & 13 & 2200 \\
\hline
\end{tabular}

Note: a Determined by the Cockcroft-Gault method.

Abbreviations: F, female; M, male; DA, dopamine; NE, norepinephrine; CLCr, creatinine clearance; SOFA, Sequential (Sepsis-related) Organ Failure Assessment. 

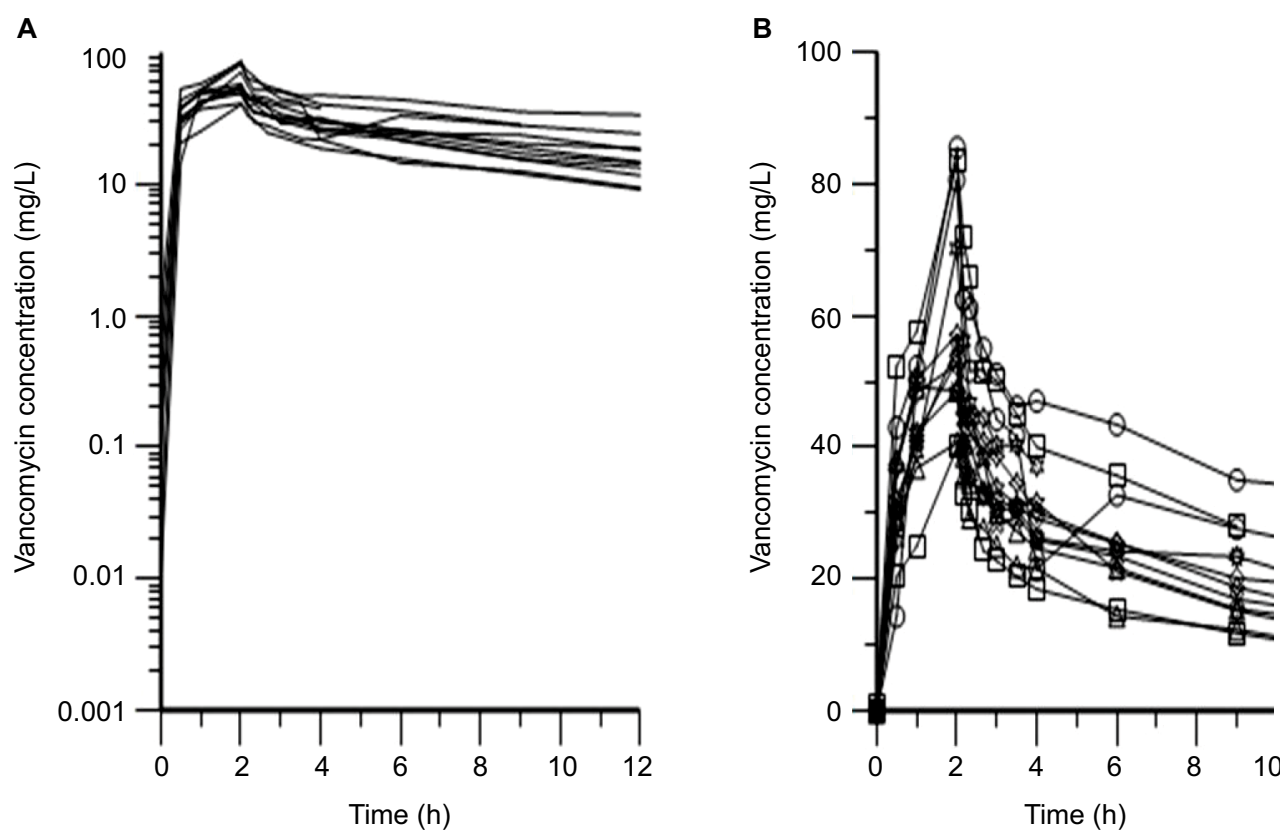

Figure I Semilogarithmic plots of the observed serum vancomycin concentration-time curve (A) and observed vancomycin concentrations versus time curve (B) in twelve patients.
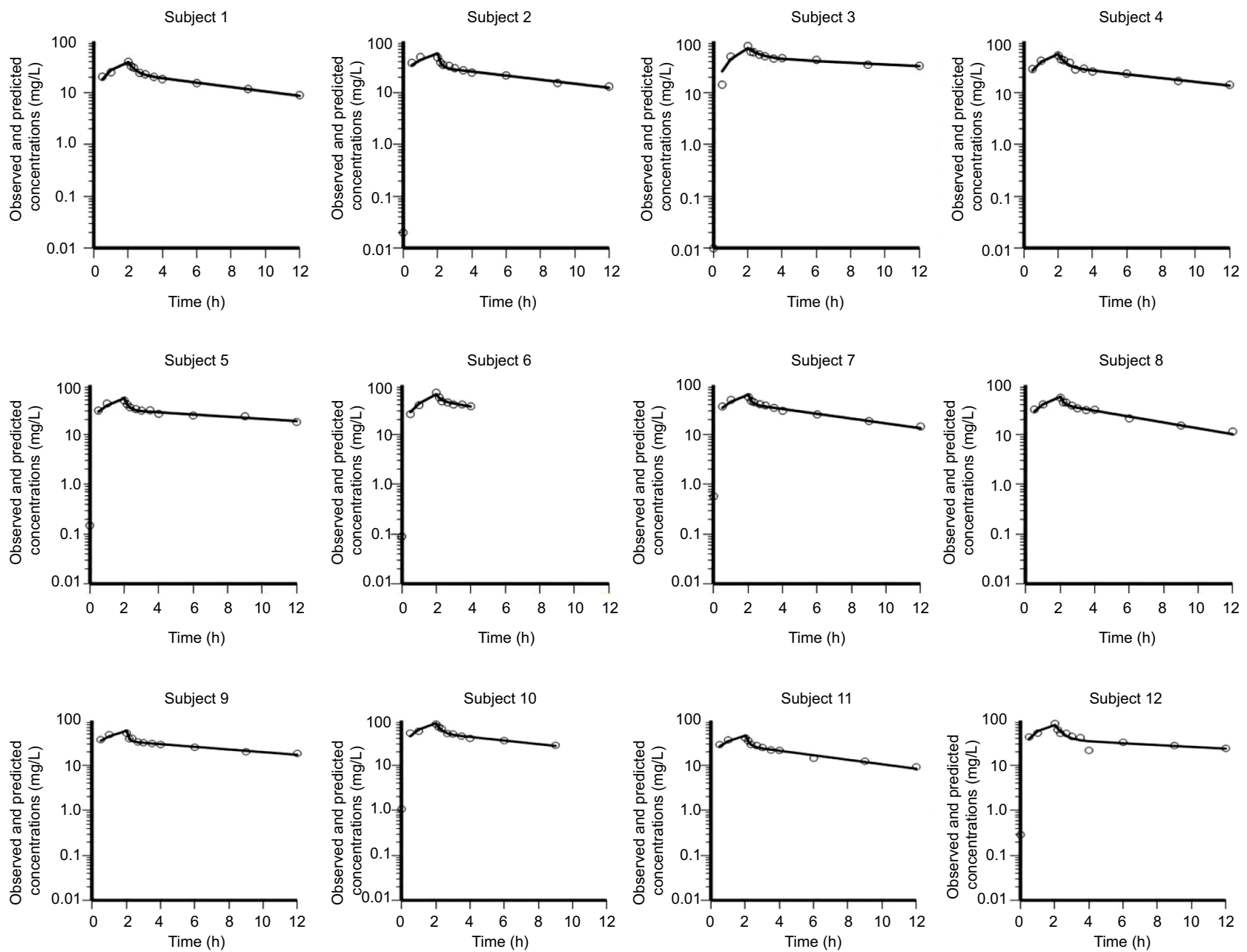

Figure 2 Observed $(\mathrm{O})$ and predicted $(-)$ vancomycin concentration versus time plots using two-compartmental model analysis for individual subjects receiving vancomycin $30 \mathrm{mg} / \mathrm{kg}$ infused over $2 \mathrm{~h}$. 
Table 2 Patient's pharmacokinetic parameter estimates using non-compartment model analysis

\begin{tabular}{|c|c|c|c|c|c|c|c|}
\hline Subjects & $\operatorname{Ke}\left(h^{-1}\right)$ & $R_{\text {adj }}^{2}$ & Half-life (h) & CLss (L/h) & Vss (L) & $A \cup C_{0 \rightarrow 12}(\mathrm{~h} \cdot \mathrm{mg} / \mathrm{L})$ & $A \cup C 0_{0 \rightarrow 24, s s}(h \cdot m g / L)$ \\
\hline Subject I & 0.089 & 1.000 & 7.77 & 7.36 & 72.81 & 203.91 & 270.71 \\
\hline Subject 2 & 0.083 & 0.919 & 8.40 & 5.21 & 54.53 & 287.76 & 387.50 \\
\hline Subject 3 & 0.044 & 0.775 & 15.68 & 4.78 & 108.25 & 502.45 & 809.19 \\
\hline Subject 4 & 0.083 & $0.94 I$ & 8.36 & 6.72 & 73.40 & 297.41 & 405.03 \\
\hline Subject 5 & 0.050 & 0.672 & 13.92 & 6.23 & 111.51 & 320.78 & 486.49 \\
\hline Subject 7 & 0.093 & 0.994 & 7.44 & 5.97 & 56.50 & 335.01 & 440.30 \\
\hline Subject 8 & 0.101 & 0.996 & 6.85 & 5.77 & 48.27 & 294.56 & 374.67 \\
\hline Subject 9 & 0.053 & 0.873 & 12.99 & 5.15 & 85.92 & 330.37 & 492.57 \\
\hline Subject II & 0.072 & 0.984 & 9.54 & 8.05 & 84.40 & 223.62 & 298.73 \\
\hline Subject 12 & 0.073 & 0.938 & 13.30 & 5.27 & 91.74 & 417.59 & 631.18 \\
\hline Mean \pm SD & $0.072 \pm 0.021$ & $0.910 \pm 0.110$ & $10.42 \pm 3.21$ & $6.05 \pm 1.06$ & $78.73 \pm 21.78$ & $321.34 \pm 86.98$ & $459.64 \pm 160.13$ \\
\hline $\begin{array}{l}\text { Median } \\
\text { (min-max) }\end{array}$ & $\begin{array}{l}0.078 \\
(0.044-0.101)\end{array}$ & $\begin{array}{l}0.940 \\
(0.672-1.000)\end{array}$ & $\begin{array}{l}8.93 \\
(6.85-15.68)\end{array}$ & $\begin{array}{l}5.87 \\
(4.78-8.05)\end{array}$ & $\begin{array}{l}78.90 \\
(48.27-111.51)\end{array}$ & $\begin{array}{l}309 \\
(203.91-502.45)\end{array}$ & $\begin{array}{l}422.67 \\
(270.7 \mid-809.19)\end{array}$ \\
\hline
\end{tabular}

Abbreviations: Ke, elimination rate constant; $R_{\text {adj }}^{2}$ adjusted R-squared; CLss, clearance and volume of distribution of vancomycin at steady state; Vss, volume of distribution at steady state; $A \cup C_{0 \rightarrow 12}$, area under the serum concentration-time curve from time zero to $12 \mathrm{~h} ; \mathrm{AUC}_{0 \rightarrow 24,5,}, \mathrm{AUC}_{0 \rightarrow 24}$ at steady state; SD, standard deviation; min, minimum; max, maximum.

Table 3 Summary of pharmacokinetic parameter estimates using a two-compartmental model

\begin{tabular}{lll}
\hline Parameters & Mean \pm SD & Median (min-max) \\
\hline $\mathrm{CL}(\mathrm{L} / \mathrm{h})$ & $3.70 \pm \mathrm{I} .25$ & $3.87(\mathrm{I} .73-5.97)$ \\
$\mathrm{CLd}(\mathrm{L} / \mathrm{h})$ & $22.67 \pm 5.50$ & $23.25(14.17-30.83)$ \\
$\mathrm{Vc}_{\mathrm{c}}(\mathrm{L})$ & $8.34 \pm 4.36$ & $7.33(3.60-18.7 \mathrm{I})$ \\
$\mathrm{Vc}_{\mathrm{c}}(\mathrm{L} / \mathrm{kg})$ & $0.13 \pm 0.06$ & $0.12(0.06-0.26)$ \\
$\mathrm{VP}_{\mathrm{P}}(\mathrm{L})$ & $30.99 \pm 7.84$ & $3 \mathrm{I} .60(19.02-45.6 \mathrm{I})$ \\
$\mathrm{VP}_{\mathrm{P}}(\mathrm{L} / \mathrm{kg})$ & $0.50 \pm 0.14$ & $0.5 \mathrm{I}(0.32-0.70)$ \\
\hline
\end{tabular}

Abbreviations: $S D$, standard deviation; min, minimum; max, maximum; $C L$, total clearance; CLd, inter-compartmental clearance; $\mathrm{Vc}$, volume of the central compartment; $V_{p}$, volume of peripheral compartment.

patients' weight was observed to be related with the values of vancomycin Vss $\left(\right.$ Vss $=0.2554 \times($ weight $\left.)+42.794, r^{2}=0.330\right)$.

As for the model-dependent analysis, serum vancomycin concentration-time curves were fit to one, two, and three compartmental first-order elimination models. Based on the AKI and the Schwarz Bayesian criterion, the three-compartment model was best fit for the vancomycin concentration-time data of patients numbered 7,8 , and 9 , while the two-compartment model was best fit for the rest of the patients.

The two-compartment analysis was performed in order to summarize the characteristics of vancomycin PK among this population. The PK parameters were summarized in Table 3. The median systemic and distributive clearance values of vancomycin are $3.87 \mathrm{~L} / \mathrm{h}$ (range $1.73-5.97 \mathrm{~L} / \mathrm{h}$ ) and $23.25 \mathrm{~L} / \mathrm{h}$ (range 14.17-30.83 L/h), respectively. The median central and peripheral volume of distribution values of vancomycin are 7.33 L (range 3.60-18.71 L) and 31.60 L (range 19.02-45.61 L), respectively. The scatter plot of observed against predicted concentrations of the 12 patients with septic shock, using the two-compartmental first-order elimination model is shown in Figure 3. The observed vancomycin concentrations fell on and

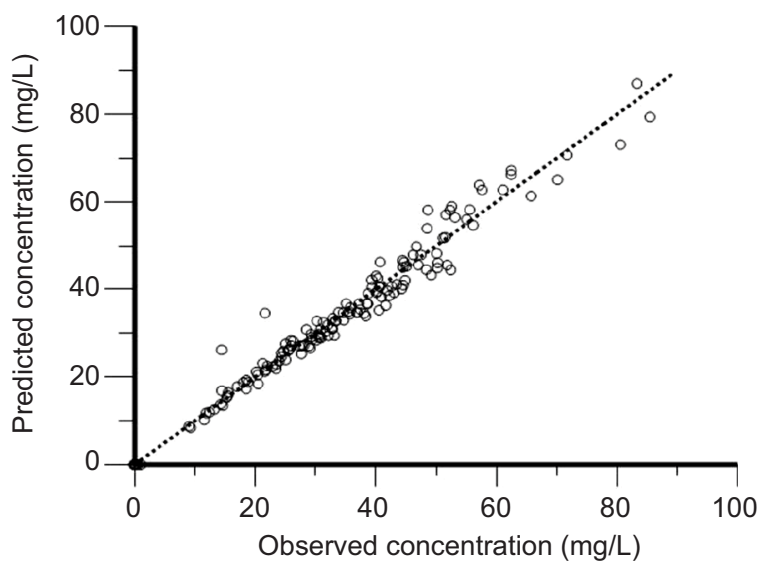

Figure 3 Scatter plot of observed against predicted concentrations of twelve septic shock patients (two-compartment model).

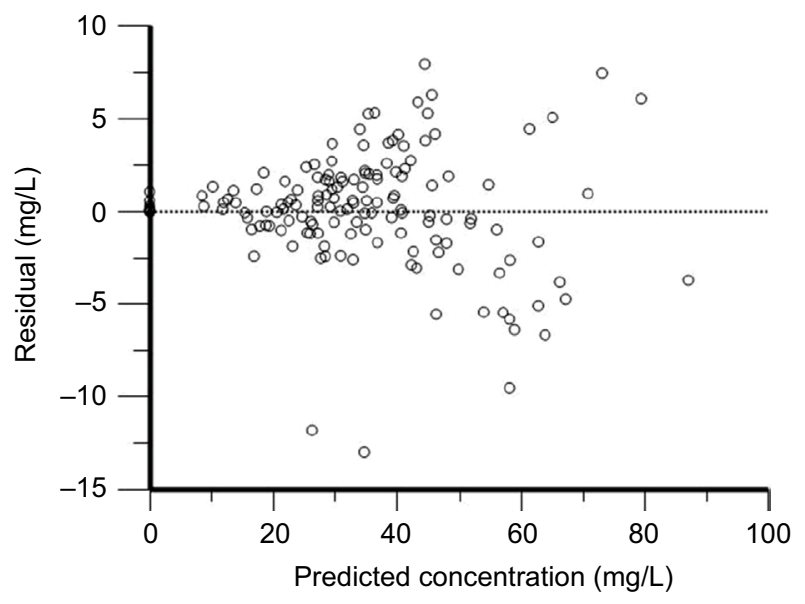

Figure 4 Scatter plot of predicted concentrations against weighted residuals of twelve septic shock patients (two-compartment model).

equally all along both sides of the line of unity. Figure 4 presents the scatter plot of residual versus predicted vancomycin concentrations from the same model analysis. The residual values were roughly equally distributed on both sides of the zero line. 
The correlation between patients' demographic, clinical data and PK parameters were explored. Systemic $\left(r^{2}=0.286\right)$ and distributive $\left(r^{2}=0.370\right)$ clearance values were found as weakly correlated with the SOFA score. The higher the SOFA score, the lower the systemic and distributive clearance values. However, vancomycin clearance and creatinine clearance ( $\left.r^{2}=0.280\right)$ as well as vancomycin central volume of distribution and weight $\left(r^{2}=0.275\right)$ were observed as poorly correlated. The probability of target attainments, achieving the target $\mathrm{AUC}_{24} / \mathrm{MIC} \geq 400$, with different MIC values of vancomycin for MRSA using different vancomycin dosage regimens were summarized and presented in Figure 5.

\section{Discussion}

Vancomycin PK analyses were conducted by using the noncompartment and compartment models. The majority of the vancomycin concentration-time profiles in patients with septic shock were best fit to the two-compartment model. It was found that the clearance values in the studied patients were higher when compared with the patients without septic shock during the initial phase. The values of vancomycin volume of distribution observed in this study were similar to the result in non-septic shock patients. Patients with septic shock seemed to clear vancomycin faster than the critically ill patients. However, no difference was detected in the distribution of vancomycin in both populations.

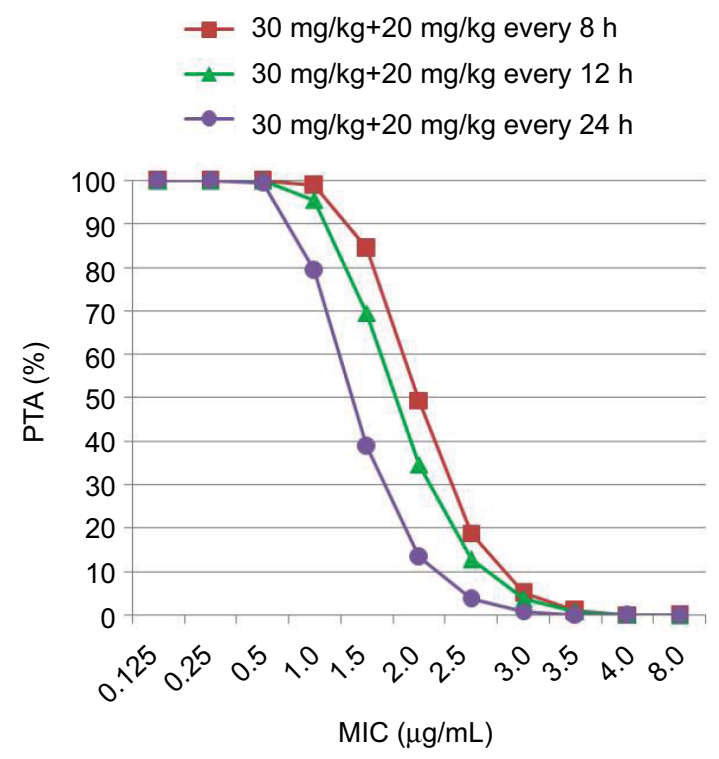

Figure 5 The probability of target attainments (PTA), achieving the target $\mathrm{AUC}_{24}$ I MIC $\geq 400$, with different MIC values of vancomycin for MRSA using different vancomycin dosage regimens.

Abbreviations: $\mathrm{AUC}_{24} / \mathrm{MIC}, 24-\mathrm{h}$ area under the vancomycin concentrationtime curve/minimum inhibitory concentration; h, hours; MRSA, methicillin-resistant staphylococcus aureus.
In septic shock patients, the values of vancomycin volume of distribution from our noncompartmental and compartmental models were similar to the ones previously reported in non-septic shock phase. According to non-compartment analysis, the Vss value $(78.73 \pm 21.78 \mathrm{~L})$ was similar to the Vss value estimated by Matzke et $\mathrm{al}^{5}(63.38 \pm 23.52 \mathrm{~L})$, which was conducted in non-septic shock patients. When using two-compartment model, the estimated mean $\mathrm{Vc}$ value (Table 3) was $8.34 \pm 4.36 \mathrm{~L}$, which was similar to the values (Vc of $12 \pm 4 \mathrm{~L}$ ) reported by Polard et al. ${ }^{6}$ However, Purwonugroho et $\mathrm{al}^{7}$ reported higher values of $\mathrm{Vc}(36.11 \mathrm{~L})$ in Thai adult patients. One-third of patients in Purwonugroho et $\mathrm{al}^{7}$ study were in ICU. Similarly, the mean volume of peripheral compartment $(\mathrm{Vp}=30.99 \pm 7.84 \mathrm{~L})$ in the present study was similar to Polard et $\mathrm{al}^{6}(39 \pm 12 \mathrm{~L})$, but less than Purwonugroho et $\mathrm{al}^{7}(44.2 \mathrm{~L})$.

The difference in the $\mathrm{Vc}$ and $\mathrm{Vp}$ values between the present study and Purwonugroho et $\mathrm{al}^{7}$ may result from the different time in obtaining vancomycin serum concentration. Purwonugroho et $\mathrm{al}^{7}$ obtained vancomycin $\mathrm{Vc}$ and $\mathrm{Vp}$ at steady state, while the present study investigated vancomycin PK at non-steady state condition (during the first $12 \mathrm{~h}$ of vancomycin therapy). The $\mathrm{Vc}$ and $\mathrm{Vp}$ on the first day of therapy and at steady state might be different due to the following explanations. ${ }^{6}$ During the acute phase of septic shock, the capillary permeability increased which resulted in extravascular fluid sequestration. In addition, most patients received vigorous fluid resuscitation. However, in the initial phase of septic shock, the fluid leak and fluid resuscitation may not be accumulated long enough to increase the volume of distribution of vancomycin. In the later phase of septic shock which may reflect the vancomycin serum concentration at steady state, the large amounts of fluids leaking into the interstitium led to prolonged water accumulation. Therefore, the higher value of vancomycin $\mathrm{Vd}$ was observed in this phase. This hypothesis is supported by Polard et $\mathrm{al}^{6}$ whose study observed an increase of vancomycin $V p$ at steady state $(53 \pm 38 \mathrm{~L})$ when

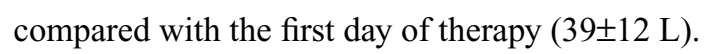

The values of vancomycin CL presented in this study (non-compartment model; CLss $=6.05 \pm 1.06 \mathrm{~L} / \mathrm{h}$ and twocompartment model; $\mathrm{CL}=3.70 \pm 1.25 \mathrm{~L} / \mathrm{h}$ ) were higher than the result obtained from other studies conducted in Thai patients without septic shock. The values of vancomycin CLss from the studies by Jaruratanasirikul et al, ${ }^{8}$ using non-compartment model and Purwonugroho et al, using two-compartment model were $1.46 \pm 0.88 \mathrm{~L} / \mathrm{h}$ and $1.54 \mathrm{~L} / \mathrm{h}$, respectively. Furthermore, the estimated value of $\mathrm{CL}$ in the present study was higher than the result in critically ill 
patients by Mangin et $\mathrm{al}^{9}(\mathrm{CL}=1.55 \mathrm{~L} / \mathrm{h})$. However, Polard et $\mathrm{l}^{6}$ reported a similar result as the present study (vancomycin $\mathrm{CL}$ of $8.58 \mathrm{~L} / \mathrm{h}$ ) in a population of critically ill patients during the first dose of vancomycin administration. In addition, Polard et $\mathrm{al}^{6}$ reported a significant decrease $(\sim 30 \%)$ in the mean value of vancomycin clearance at steady state.

The higher values of vancomycin clearance may result from the compensation of non-renal clearance during acute kidney injury and the effect of inotropic drugs. First, the majority of patients with septic shock had acute kidney injury. During acute kidney injury, non-renal clearance of vancomycin may increase. Our hypothesis is supported by a study of vancomycin PK in critically ill patients with acute kidney injury. The result of that study suggested that substantial portion of the non-renal clearance of vancomycin is preserved during the early phase of acute kidney injury. ${ }^{10}$ Second, inotropic and vasoactive drugs, such as dopamine, dobutamine, and norepinephrine, used during the initial phase of septic shock may play an important role in enhancing vancomycin clearance by increasing cardiac output. ${ }^{11}$ Most patients in the study received these agents.

Infectious Diseases Society of America (IDSA) guideline suggests that $\mathrm{AUC}_{24} / \mathrm{MIC}$ of $400 \mu \mathrm{g} \cdot \mathrm{h} / \mathrm{mL}$ is the $\mathrm{PK} /$ pharmacodynamic (PD) parameter that relates to good clinical and bacteriological outcomes for patients with MRSA infection. ${ }^{12}$ The present study observed the increase in vancomycin CL, but not for the volume of distribution in the patients with early phase of septic shock. By giving the loading dose of vancomycin, six out of ten patients in the study achieved the PK-PD target $\left(\mathrm{AUC}_{24}>400 \mu \mathrm{g} \cdot \mathrm{h} / \mathrm{mL}\right)$. However, four patients have subtherapeutic PK-PD target. Thus, to achieve an AUC/ $\mathrm{MIC}_{24}$ target, it was suggested that the loading dose of 30 $\mathrm{mg} / \mathrm{kg}$, followed by a maintenance dose of $20 \mathrm{mg} / \mathrm{kg}$ every $8 \mathrm{~h}$ to compensate for the increase of vancomycin CL in the early phase of septic shock.

\section{Limitations}

There are some limitations found in this study that should be noted. First, due to the nature of PK studies, the study lacks an evaluation of patient outcomes. Second, the sample size may be insufficient. However, in the absence of data from a larger sample size, the study remains the only one conducted with patients with initial phase of septic shock. ${ }^{13}$ Third, the Cockcroft-Gault method used in estimating CLCr in this study is known to have certain limitations in severely ill patients. ${ }^{14,15}$ Fourth, the narrow range of patient weights and a lack of obese patients in this study which may limit its external validity. Finally, this study only evaluated the early phase of septic shock; hence, it should not be used in extrapolating parameters beyond this time frame.

\section{Conclusion}

In the early phase of septic shock, the value of total clearance of vancomycin increased while the values of central and peripheral compartment volume of distribution did not increase. According to the observations of this study (Figure 5), loading dose of $30 \mathrm{mg} / \mathrm{kg}$ vancomycin and subsequent dose of $20 \mathrm{mg} / \mathrm{kg}$ every $8 \mathrm{~h}$ to achieve $\mathrm{AUC}_{24} / \mathrm{MIC}$ $>400 \mu \mathrm{g} \cdot \mathrm{h} / \mathrm{mL}$ on the first day of therapy were recommended. Finally, therapeutic drug monitoring is required for further dosage adjustments.

\section{Acknowledgments}

This study was sponsored by the Faculty of Medicine and Faculty of Pharmaceutical Sciences, Prince of Songkla University. The authors would like to thank the Certara Company for the Academic Licenses for the Phoenix WinNonlin Version 6.3, Phoenix NLME 1.2, and Pharsight Trial Simulator ${ }^{\mathrm{TM}}$ Version 2.2.2, with special thanks to Dr Gary H Smith for English editing of the manuscript.

\section{Disclosure}

The authors report no conflicts of interest in this work.

\section{References}

1. Vázquez M, Fagiolino P, Boronat A, Buroni M, Maldonado C. Therapeutic drug monitoring of vancomycin in severe sepsis and septic shock. Int J Clin Pharmacol Ther. 2008;46:140-145.

2. Roberts JA, Lipman J. Pharmacokinetic issues for antibiotics in the critically ill patient. Crit Care Med. 2009;37:840-851.

3. del Mar Fernández de Gatta Garcia M, Revilla N, Calvo MV, Domínguez-Gil A, Sánchez Navarro A. Pharmacokinetic/pharmacodynamic analysis of vancomycin in ICU patients. Intensive Care Med. 2007;33: 279-285.

4. Cockcroft DW, Gault MH. Prediction of creatinine clearance from serum creatinine. Nephron. 1976;16:31-41.

5. Matzke GR, McGory RW, Halstenson CE, Keane WF. Pharmacokinetics of vancomycin in patients with various degrees of renal function. Antimicrob Agents Chemother. 1984;25:433-437.

6. Polard E, Le Bouquin V, Le Corre P, et al. Non steady state and steady state PKS Bayesian forecasting and vancomycin pharmacokinetics in ICU adult patients. Ther Drug Monit. 1999;21:395-403.

7. Purwonugroho TA, Chulavatnatol S, Preechagoon Y, Chindavijak B, Malathum K, Bunuparadah P. Population pharmacokinetics of vancomycin in Thai patients. Sci World J. 2012;2012:762649.

8. Jaruratanasirikul S, Julamanee J, Sudsai T, Saengsuwan P, Jullangkoon $\mathrm{M}$, Ingviya $\mathrm{N}$, Jarumanokul R. Comparison of continuous infusion versus intermittent infusion of vancomycin in patients with methicillinresistant Staphylococcus aureus. J Med Assoc Thai. 2010;93:172-176.

9. Mangin O, Urien S, Mainardi JL, Fagon JY, Faisy C. Vancomycin pharmacokinetic and pharmacodynamic models for critically ill patients with post-sternotomy mediastinitis. Clin Pharmacokinet. 2014;53:849-861.

10. Macias WL, Mueller BA, Scarim SK. Vancomycin pharmacokinetics in acute renal failure: preservation of nonrenal clearance. Clin Pharmacol Ther. 1991;50:688-694. 
11. Pea F, Porreca L, Baraldo M, Furlanut M. High vancomycin dosage regimens required by intensive care unit patients cotreated with drugs to improve haemodynamics following cardiac surgical procedures. J Antimicrob Chemother. 2000;45:329-335.

12. Rybak M, Lomaestro B, Rotschafer JC, et al. Therapeutic monitoring of vancomycin in adult patients: a consensus review of the American Society of Health-System Pharmacists, the Infectious Diseases Society of America, and the Society of Infectious Diseases Pharmacists. Am J Health Syst Pharm. 2009;66:82-98.
13. Roberts JA, Kirkpatrick CMJ, Lipman J. Monte Carlo simulations: maximizing antibiotic pharmacokinetic data to optimize clinical practice for critically ill patients. J Antimicrob Chemother. 2011;66: 227-231.

14. Martin JH, Fay MF, Udy A, et al. Pitfalls of using estimations of glomerular filtration rate in an intensive care population. Intern Med J. 2011;41: 537-543.

15. Tanaka A, Suemaru K, Araki H. A new approach for evaluating renal function and its practical application. J Pharmacol Sci. 2007;105:1e5.
Infection and Drug Resistance

\section{Publish your work in this journal}

Infection and Drug Resistance is an international, peer-reviewed openaccess journal that focuses on the optimal treatment of infection (bacterial, fungal and viral) and the development and institution of preventive strategies to minimize the development and spread of resistance. The journal is specifically concerned with the epidemiology of antibiotic resistance and the mechanisms of resistance development and diffusion in both hospitals and the community. The manuscript management system is completely online and includes a very quick and fair peerreview system, which is all easy to use. Visit http://www.dovepress.com/ testimonials.php to read real quotes from published authors. 